\section{Numb Chin Syndrome: Diagnostic Significance 0ver 57 Years and Review of 550 Patients in the Literature Worldwide}

Keywords: Numb chin syndrome; Mental neuropathy; Mental nerve numbness; Lymphoma; Leukemia; Brain; Bone; Breast; Prostate; Cancer

\begin{abstract}
Numb Chin Syndrome (NCS) is a heterogeneous condition of mental nerve neuropathy playing in concert with multiple disease mechanisms, but all result in a disruption of unilateral or bilateral facial nerves, fever, and swelling of the lower lip. The NCS has been reported as a prodromal symptom of pending malignancies, a possible precursor of cancer or leukemia, and sometimes merely a benign, painful or annoying, condition. However, any causal relationships between the NCS and malignancy have not been made, were not aggregated, and therefore remain unclear. This thorough review of all the available current literature in the PubMed interface was performed by using the key words, "mental neuropathy," "mental nerve numbness," and "numb chin syndrome." There were 186 peerreviewed articles reporting 550 patients from 28 countries worldwide including 150 benign, 398 malignant, and 2 unknown cases. The seven most common malignancies from high to low frequency were: lymphoma, bone cancer, oral cancer, breast cancer, brain cancer leukemia, and prostate cancer. While the clinical implications of the NCS are not fully understood, this delineative study will aid physician confronted and confounded with various malignancies, neuropathies, and cytogenetic abnormalities of patients initially presenting with the symptom of a numb chin.
\end{abstract}

\section{Abbreviations}

HIV: Human Immunodeficiency Virus; MRI: Magnetic Resonance Imagining; NCS: Numb Chin Syndrome; USA: United States of America

\section{Introduction}

Numb Chin Syndrome (NCS) is a set of neuropathological symptoms including lower facial numbness, due to paralysis of the distal trigeminal nerve, especially right, unilateral, dysesthesia or paresthesia (numbness) of the chin, local fever, swelling, redness, persistent pain, a thickening sensation of the lower lip, and dullness in the mandible. When contemplating this worldwide, not too rare disease of the numb chin, a mental image of Rodin's famous bronze statue, "The Thinker" comes to mind. He is pressing the back of his right hand to the right side of his chin, right elbow to his left knee. Is he applying presure to alleviate some pain, feeling numbness in his chin, contemplating some kind of worsening condition? Or what? We wonder. Sitting in this position, what is he thinking?

In the beginning in London, Charles Bell first described this syndrome in 1830 in a woman with breast cancer and noting mental nerve anesthesia in patients presenting with trauma to the jaw and retromandibular tumors [1]. In the United States of America, numb

\section{Journal of}

Syndromes

\section{Robert E. Brandt ${ }^{1,2^{*}}$, Akihiro Takeuchi ${ }^{2}$ and Hirotoshi Kamata ${ }^{3}$}

${ }^{\prime}$ MedEd Japan, Tokyo, Japan

${ }^{2}$ Department of Medical Informatics, Kitasato University School of Medicine, Kanagawa, Japan

${ }^{3}$ Department of Hematology, Kitasato University School of

Medicine, Kanagawa, Japan

\section{${ }^{*}$ Address for Correspondence}

Robert E. Brandt, MedEd Japan, Department of Medical Informatics, Kitasato University School of Medicine, Kanagawa, 3-2-12 Eifuku, Suginami, Tokyo 168-0064, Japan, Tel: +81-3-5930-4568, Fax: +81-42 778-9176; E-mail: robert_e_brandt@hotmail.com

Submission: June 10, 2020

Accepted: July 17, 2020

Published: July 21, 2020

Copyright: () 2020 Brandt RE, et al. This is an open access article distributed under the Creative Commons Attribution License, which permits unrestricted use, distribution, and reproduction in any medium, provided the original work is properly cited.

chin was first mentioned as a syndrome, in 1963 as an innocuous symptom, albeit an ominous one, that would indicate metastasis and manifest malignancy [2]. In Japan, the NCS was first reported in 1989 as the initial manifestation of a case of Burkitt's lymphoma [3].

Now, 190 years after Bell's first mention of it [1], we have attempted to determine if the fulminant numb chin is an ominous sign of an upcoming malignancy, a prodromal syndrome of a life threatening disease, or merely a benign but painful nuisance. Although there have been various reviews reporting malignancies and diseases associated with a numb chin, they focus on certan kinds of malignancies, such as lymphoma, leukemia, lung, breast, brain, bone, and prostrate cancers, among other major noncancerous maladies. The aim of this study was, therefore, to summarize all of the reported cases of the NCS from all over the world for the last 57 years, looking into benign and malignant cases, to determine if there were any patterns that may suggest or even prove causality.

\section{Subjects and Methods}

An NCS review was performed of all the available current literature in the PubMed interface, during the 57 -year period from 1963 to 2020. The key words "mental neuropathy," "mental nerve numbness," and "numb chin syndrome" generated a considerable body of literature comprised of 186 relevant, peer-reviewed articles. The reported cases were manually counted for the various signs and symptoms, histories, diagnoses, treatments, prognoses, and actual outcomes.

\section{Results}

A retrospective analysis of 186 articles revealing 550 patients, who presented with signs and symptoms of the NCS at 122 sites in 28 countries throughout Europe $(\mathrm{n}=198)$, North and South America ( $\mathrm{n}$ $=177)$, the Middle East $(\mathrm{n}=107)$ and the Asia/Pacific region $(\mathrm{n}=68)$, composed this exhaustive study. The range in patients' ages was from 


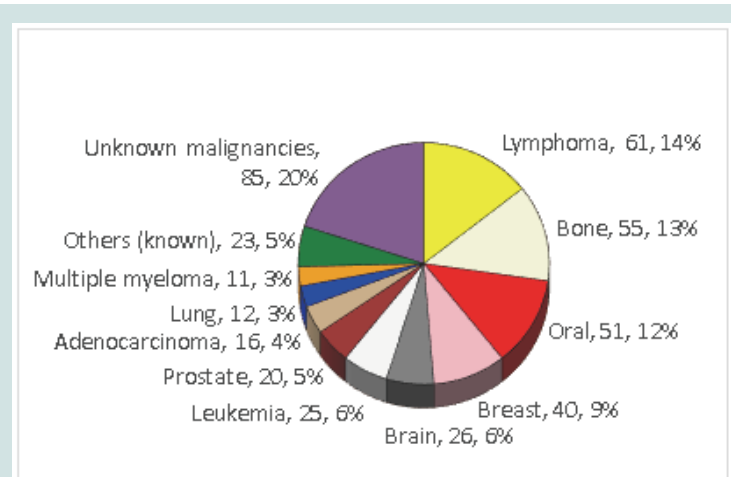

Figure 1: Cancer types and unknown malignancies associated with NCS.

7 to 82 years old with middle-age to elderly patients affected most and 337 patients for whom age was not reported. Regarding gender, there were 88 men, 98 women, and 364 patients for whom gender was not reported.

Patients presenting at the dental office or at their local healthcare clinic with lower facial numbness in the area of the distal trigeminal nerve, numbness of the chin, especially the right side, local fever, swelling, redness, persistent pain, a thickening sensation of the lower lip, and an aching and dullness in the jawbone, all warrant an MRI. These signs and symptoms could likely manifest an unknown or as yet undiagnosed cancer, as discovered in 86 of 550 patients, or they could be the first prodromal set of symptoms manifesting a systemic malignancy, as it was for 29 patients in the present series. Worldwide, of 550 reported NCS patients there were 150 benign cases $(27 \%)$ and malignancies in 398 (72\%) including 63 deaths (11\%). Two cases were not reported whether they were begin or malignant, and 37 cases (7\%) were of multiple malignancies. These factors caused the discrepancy between the number of malignancies 398 versus the number of patients with malignancies $(\mathrm{n}=380)$.

The initial presentation of this group of NCS symptoms helped physicians diagnose $340(80 \%)$ of 425 cases as one of the 23 cancer types (Table 1). The seven most common malignancies from high to low frequency were: lymphoma $(n=61,15 \%)$, bone cancer $(n=55$, $14 \%)$, oral cancer $(n=51,13 \%)$, breast cancer $(n=40,9 \%)$, brain cancer $(n=26,7 \%)$, leukemia $(n=25,6 \%)$, and prostate cancer $(n=$ $20,5 \%)$. Moreover, of the 398 (72\%) malignancies, there were 37 (9\%) cases of multiple malignancies, 29 (7\%) systemic malignancies, and as many as 85 (20\%) unspecified malignancies (Figure 1).

With the advances in diagnostics, although the terminology and classifications of hematopoetic and lymphoid tumours continue to evolve and change, the counting in this study was done according to the diagnoses at the time of each of those published reports. Lymphoma $(\mathrm{n}=61)$ was subclassified as: B-cell lymphoma $(\mathrm{n}=$ 17), Hodgkin $(\mathrm{n}=2)$ and non-Hodgkin lymphoma $(\mathrm{n}=8)$, Burkitt lymphoma $(\mathrm{n}=9)$, and lymphoblastic lymphoma $(\mathrm{n}=2)$. Leukemia $(\mathrm{n}=25)$ was subclassified into acute lymphoblastic leukemia $(\mathrm{n}=$ $8)$, acute myeloid leukemia $(n=2)$, and Burkitt's leukemia $(n=10)$. There were 31 patients presenting with the symptoms of NCS who were diagnosed as having Burkitt (non-Hodgkin) lymphoma and/ or Burkitt's leukemia; and 3 of those 13 Burkitt's leukemia patients were HIV positive. Noteworthy, there were 11 cases of NCS related to
B-cell lymphoma and 1 case of B-cell acute lymphoblastic leukemia as the precursor to NCS. Multiple myeloma was reported in 11 cases. There were only 3 cases reported of NCS symptoms related to colon cancer and, fortunately but inexplicably, no cases of NCS related to pancreatic, duodenal, small bowel, rectal, or anal cancer. The specific types of malignancies of 85 (20\%) cases were not reported (Table 1).

There were 150 benign NCS cases (27\%) resolved with various therapies such as periapical surgery or resolved for unknown reasons after 3 to 14 days of being symptomatic, pain, fever, and numbness, sometimes lasting up to 2 months, as in 1 case of giant cell arteritis, also called temporal arteritis, successfully treated with oral Prednisolone [4]. There was only 1 case reported of recurrence, and that being one of multiple recurrences, four fulminant painful but benign attacks, over a period of 16 years [5]. Currently, at 70 years of age, the 5-year follow-up revealed that patient to be asymptomatic and in good health.

\section{Discussion}

This study showed that a numb chin and a fat lip correlated with malignancy more often than might otherwise be expected in as many as 398 (72\%) of 550 NCS patients. First mention of the syndrome of the numb chin in the United States of America was in 1963 [2]. In Spain, in 2008, it was reported that this symptom may be the first manifestation of systemic cancer [6], a symptom of spread of an established tumor, or a sign of infiltration in an intraoral lesion [6]. Moreover, in that study, 18 of 22 patients (82\%) died before a mean of 20 months after the initial presentation, further showing that these symptoms are mostly indicative of very poor prognoses [6]. By 2014 , only 6 years later, and as many as 83 cases had been reported worldwide; and reported in Germany it was reported NCS was a "rare" and often overlooked symptom of extracranial malignancies [7].

Beginning in 1963 through 2018, 546 cases were reported around the world in those 55 years, amounting to an average of 10 new NCS cases being reported annually. Notwithstanding, Malaysia and Japan reported the syndrome as seemingly rare in their countries but manifesting malignancy and morbidity [8,9]. In Malaysia, following a mastectomy for stage 2 breast carcinoma, a 51-year-old woman presented with 2 weeks of bilateral lower limb pain and left chin numbness. She was diagnosed with the NCS secondary to mandibular tumour metastasis, started on palliative chemotherapy and radiation, and eventually discharged with the only lingering complaint of a numb chin [8]. In Japan, the oldest and youngest patients presenting with NCS symptoms were a 73-year-old patient with prostate cancer and an 18-year-old boy with Burkitt's lymphoma/leukemia. They both were reported as having succumbed to their illnesses in the hospital [9].

Collectively these results, from 28 countries in this 57 -year longitudinal worldwide study of 186 articles in the medical literature reporting NCS events and outcomes, could be important to physicians with respect to performing further examinations to make more accurate diagnoses and earlier treatment decisions for patients presenting with the initial symptoms of the NCS. The study revealed that patients presenting with a numb chin, intractable pain and a thickening sensation of the lower lip, ought to be carefully followed 
Table 1: NCS related cancer cases.

\begin{tabular}{|c|c|c|c|}
\hline Cancer types & $n$ & $\%$ & References $^{*}$ (If $n>1$ case $^{(n=x)}$ is given.) \\
\hline Lymphoma & 61 & 14 & $3,15(\mathrm{n}=9), 23,24,25,36(\mathrm{n}=3), 37(\mathrm{n}=2), 38(\mathrm{n}=2), 59,63(\mathrm{n}=4), 65,73,76(\mathrm{n}=4), 77,80,82(\mathrm{n}=4), 86,87(\mathrm{n}=5), 90,99,110,115,120,127,130,134,139,143,152,155,163,168,169,177,179,183$ \\
\hline Bone & 55 & 13 & $2,9,14,35(\mathrm{n}=2), 37(\mathrm{n}=23), 42(\mathrm{n}=3), 63(\mathrm{n}=3), 75,78,131,136,137,140,143(\mathrm{n}=5), 145,161,162,163,167,170,171,174,182,184$ \\
\hline Oral & 51 & 12 & $60,100(\mathrm{n}=22), 104(\mathrm{n}=5), 108,110,143(\mathrm{n}=5), 176,181(\mathrm{n}=15)$ \\
\hline Breast & 40 & 9 & $7(\mathrm{n}=13), 20,55,70,89,94,103,116,126,129,136,137,143(\mathrm{n}=2), 148,151(\mathrm{n}=7), 161,164(\mathrm{n}=2), 174(\mathrm{n}=4), 182,184$ \\
\hline Brain & 26 & 6 & $26,29,37(n=9), 76(n=2), 80,96(n=4), 115,140,145,151,158,173,174(n=2)$ \\
\hline Leukemia & 25 & 6 & $17(\mathrm{n}=2), 19,33,34,45,54(\mathrm{n}=3), 58,77,81,88,98,101,123,124,128,129,133,147,168,174,185,186$ \\
\hline Prostate & 20 & 5 & $35,38,42(\mathrm{n}=3), 68,70,72,74,75,92,97,131,151(\mathrm{n}=2), 154,167,170,174,185$ \\
\hline Adenocarcinoma & 16 & 4 & $14,29,42(\mathrm{n}=3), 87,89,131,140,142,156,158,167,170,176,185$ \\
\hline Lung & 12 & 3 & $29,53,70,93,122,140,142,145,162,173,174,175$ \\
\hline Multiple myeloma & 11 & 3 & $46,57,74,84,108,151(\mathrm{n}=2), 166,174(\mathrm{n}=2), 178$ \\
\hline Sarcoma & 4 & 1 & $9,71(n=2), 121$ \\
\hline Skin & 4 & 1 & $18(\mathrm{n}=3), 38$ \\
\hline Colon & 3 & 1 & $138(n=2), 174$ \\
\hline Bladder & 2 & 0.5 & 47,162 \\
\hline Esophageal & 2 & 0.5 & 113,156 \\
\hline Stomach & 1 & 0.2 & 158 \\
\hline Liver & 1 & 0.2 & 140 \\
\hline Adenoid & 1 & 0.2 & 174 \\
\hline Renal & 1 & 0.2 & 118 \\
\hline Adrenal & 1 & 0.2 & 174 \\
\hline Uterine & 1 & 0.2 & 143 \\
\hline Mediastinal & 1 & 0.2 & 143 \\
\hline Plasmocytoma & 1 & 0.2 & 143 \\
\hline Cancer type unknown & 85 & 20 & $4(\mathrm{n}=6), 7(\mathrm{n}=2), 8(\mathrm{n}=29), 31(\mathrm{n}=7), 32(\mathrm{n}=15), 50(\mathrm{n}=4), 61,67,69(\mathrm{n}=2), 70(\mathrm{n}=2), 119,181(\mathrm{n}=15)$ \\
\hline Total & 425 & 100 & \\
\hline Multiple malignancies & 37 & 9 & $15(\mathrm{n}=8), 35(\mathrm{n}=2), 42(\mathrm{n}=3), 63(\mathrm{n}=3), 74,75,77,96(\mathrm{n}=4), 99,129,140,145,154,158,161,162,163,170,173,177,184,185$ \\
\hline Multiple malignancies & 37 & 9 & $15(\mathrm{n}=19), 22,29(\mathrm{n}=3), 119,129,131,140,145,148$ \\
\hline
\end{tabular}

*Reference numbers are not from the text but from the Appendix (available upon request).

Each reference number represents one case unless noted otherwise in parentheses.

Unknown (i.e., not reported)

up for fear of future maladies. Physicians in Germany, Japan, and Italy, asked if this syndrome was a reflection of malignancy, an immune-mediated disease, or a harbinger of medication-related (e.g., bisphosphonate), osteonecrosis of the jaw and methotrexateassociated lymphoproliferative disorders $[7,10,11]$.

Even though the mechanism of this neurological phenomenon of the numb chin remains unclear to date, and therefore often controversial, a significant majority of cases have led to the comorbid prognoses of malignancies, as evidenced in these 398 patients including 63 (11\%) morbidities. In terms of perspective only, the $11 \%$ rate of death for NCS patients is significantly higher than the worldwide $0.7 \%$ morbidity rate of patients affected with COVID-19. The NCS deaths were those at the time of the published reports and therefore do not indicate the actual number of morbidities to date. However, with the poor prognoses of the hundreds of patients reported with these malignancies, there were likely many more morbidities related to the NCS throughout the world that went unreported. Further, worthy of note, although there were 16 cases in Taiwan, there were only 2 cases reported in China and no cases from Russia.

With hundreds of malignancies the world over, the NCS signs and symptoms were revealed to be prodromal, the first manifestations in many other severe and debilitating diseases. Of those, perhaps the most debilitating is multiple sclerosis [7, 12-15]. Fortunately, one case of multiple sclerosis presenting with the symptoms of the NCS in Germany was successfully treated with interferon-B [14]. In France, a successful treatment with rituximab was reported in a patient with mental nerve neuropathy in primary Sjogren's syndrome, the autoimmune disease often comorbid with other immune diseases, especially rheumatoid arthritis and lupus [16]. In the USA, the NCS was the initial presentation of a posttransplant lymphoproliferative disorder [17]. In Italy, there were 3 cases of sudden violent, diffuse pain in the premolar region reported [18]. In the USA, a patient successfully underwent a transoral surgical resection of an elongated, calcified, styloid process to relieve the mental nerve paresthesia and pain caused by the dynamic compression of the alveolar inferior nerve [19]. In Spain, the NCS was secondary to a solitary schwannoma [20]. And in Japan, a 39-year-old woman suffered a large solitary fibrous tumor on the infratemporal fossa [21]. Thus, as is well evidenced, all over the world, there have been and still are hundreds of cases of NCS as the initial, primary sign of oncoming maladies, the degree of severity of which becomes evident in time. Therefore, early diagnoses and adequate treatment are often the difference between life or, if neglected and undiagnosed, a possible lingering death to cancer - the difference between remission-free survival or morbidity.

Burkitt lymphoma/leukemia is the most frequent subtype of hematological malignancies in the NCS. It is highly aggressive and often presents in extranodal sites and/or as acute lymphoblastic leukemia. A leukemic phase can be observed in patients with bulky disease, typically in males, and clearly present as leukemia with peripheral blood and bone marrow involvement. In the 2016 revision of the fourth edition of the World Health Organization 
classification of myeloid neoplasms and acute leukemia, Burkitt leukemia was classified as a subtype of Burkitt lymphoma [22]. Three epidemiological subtypes are recognized, which mainly differ in geographic distribution. Endemic Burkitt lymphoma occurs in equatorial Africa and Papua New Guinea, where the jaw and other face bones are typically the sites of presentation in approximately $50 \%$ $70 \%$ of those cases $[23,24]$. While not reported per se, it is conceivable that NCS signs and symptoms are physical findings in endemic Burkitt lymphoma patients. However, sporadic Burkitt lymphoma and immunodeficiency-associated Burkitt lymphoma tumours in facial structures, particularly in the jaw are rare. Furthermore, lytic destruction of an area of bone due to myeloma and lymphoma is a common symptom because leukemia and multiple myeloma proliferates in the bone marrow. This explains the physiological causality and neuropathic association that the NCS is often observed in patients with various types of hematological malignancies.

In these 57 years, there were 29 reported cases of the numb chin suspected of being an outright prodromal symptom of various malignancies. However, as an example of the reverse occurring, a case was reported of a 22-year-old man who after achieving a complete $5+$ year remission of $\mathrm{CD}+20$ positive precursor B-ALL, presented with gradually progressive altered mentation, slurring of speech, and chin paresthesias over a 72-hour period [25]. His physical exam revealed poor concentration, dysarthria, diminished sensation over the mental area, and sialorrhea; however, the remainder of the examination was unremarkable. There was another case, reported in 2015, of NCS being the secondary symptom to cancer that had started from gastric adenocarcinoma and metastasized to the brain as leptomeningeal carcinomatosis [26]. All the other 548 cases in the present series were of NCS being the first forewarning, an alarming-type symptom of what usually turned out to be a malignant and/or metastasizing disease. Sometimes for physicians unfamiliar with the NCS, these symptoms were apparently not taken as a red flag or did not sound an alarm and malignancies or debilitating diseases were manifested at later stages in the patients' prognoses.

Remarkably, of 550 cases, 150 (27\%) were benign. Moreover, in the course of compiling these data, it was conjectured that a significant number of NCS cases worldwide must go unreported and/or lost to follow-up. There were 10 articles that did not include any numbers of patients but cautioned physicians about the various aspects of the NCS and advised them to be on the lookout for these symptoms. After a 55 year period with an average of 10 new NCS cases reported annualy, the reporting of NCS cases seems to have gone silent in 2019 because, to our knowledge, there were no new cases reported until only one in 2020. That case was in Qatar, of a 30-year-old Indian man with acute myeloid leukemia who, after being treated and discharged, returned to his home country and was lost to follow-up [27]. The facts and outcomes of these 550 cases from 28 countries on all 6 continents from around the world, corroborate those in 2014, in Germany, when it was reported that both benign and malignant diseases cause the symptoms of this syndrome to flair up, that there are many misdiagnoses, and, in a large majority of patients, the symptoms often lead to a revelation of malignancy [7].

When a patient presents complaining of a numb chin, and/ or dysesthesis, fever, and a swelling sensation of the lower lip, the overwelming findings of this report will remind physicians to see this set of signs and symptoms as "a red flag" and follow up with sufficient examinations allowing them to make the right call in the early stages of diseases to help mitigate pending threats. Therefore, we hope that this study helps guide physicians to delve further into the reaches of the human nervous system to elucidate the relationships among the NCS, paralysis of the distal trigeminal nerve, leukemia, lymphoma, bone, oral, brain, breast, and prostate cancer, metastatic adenocarcinomas, and various other confounding, life-threatening neuropathies and cytogenetic abnormalities.

\section{Study limitations}

For the purposes of compiling these data and "bean counting" in this report, we have attempted to extrapolate any and all duplicated cases in the literature. Likewise, in some articles, there were omissions discovered wherein the exact data was not reported. However imperfect, therefore, further quantitative and qualitative considerations, which may logically and scientifically aply to these data, can be made by each individual physician.

\section{Conclusion}

This 57-year, 28-country, worldwide study of 186 articles revealed 398 (72\%) malignacies in 550 patients who suffered the fulminant, fullblown symptoms of the NCS. Because significant evidence of causuality remains elusive, this research opens up avenues for future study, specifically, to examine how the NCS status affects the prediction of numerous and seemingly unrelated maladies and malignancies. With a closer look at this syndrome, early detection may reduce long hospital stays for patients suffering with cancer, and some deaths may be avoided.

\section{References}

1. Furukawa T (1988) Charles Bell's description of numb chin syndrome. Neurology 38: 331.

2. Calverley JR, Mohnac AM (1963) Syndrome of the numb chin. Arch Intern Med 112: 819-821.

3. Iwatsuji K, Fukuyama H, Shio H, Nakamura S (1989) A case of Burkitt's lymphoma with numb chin syndrome as the initial manifestation. Rinsho Shinkeigaku 29: 764-768.

4. Abilleira S, Bowler JV (2005) The numb chin syndrome as an early manifestation of giant-cell (temporal) arteritis: a case report. Headache 45 : 1411-1413.

5. Brandt RE, Takeuchi A, Hirayama T (2018) Numb Chin Syndrome with Four Fulminant Attacks in 16 Years. J Syndromes 4: 1-3.

6. Sanchis JM, Bagan JV, Murillo J, Diaz JM, Poveda R, et al. (2008) Mental neuropathy as a manifestation associated with malignant processes: its significance in relation to patient survival. J Oral Maxillofac Surg 66: 995-998.

7. Assaf AT, Jürgens TP, Benecke AW, Riecke B, Blessmann M, et al. (2014) Numb chin syndrome: a rare and often overlooked symptom. J Oral Facial Pain Headache 28: 80-90.

8. Razak A, Goh BS, Rajaran JR, Nazimi AJ (2018) Numb chin syndrome: an ominous sign of mandibular metastasis. BMJ Case Rep 2018.

9. Maeda K, Taniguchi Jl, Matsui K (2018) Two cases of numb chin syndrome diagnosed as malignant disease. Oxf Med Case Reports 2018: omy097.

10. Mishima S, Takahashi K, Tomioka T, Bessho K (2016) Numb chin syndrome as initial manifestation of bisphosphonate-related osteomyelitis of the jaw and methotrexate-associated lymphoproliferative disorders: a rare case. $\mathrm{Br} \mathrm{J}$ Oral 
Citation: Brandt RE, Takeuchi A, Kamata H. Numb Chin Syndrome: Diagnostic Significance Over 57 Years and Review of 550 Patients in the Literature Worldwide. J Syndromes. 2020;5(1): 5.

ISSN: $2380-6036$

Maxillofac Surg 54: 114-115.

11. Fortunato L, Amato M, Simeone M, Bennardo F, Barone S, et al. (2018) Numb chin syndrome: a reflection of malignancy or a harbinger of MRONJ? A multicenter experience. J Stomatol Oral Maxillofac Surg 119: 389-394.

12. Horowitz SH (1974) Isolated facial numbness. Clinical significance and relation to trigeminal neuropathy. Ann Intern Med 80: 49-53.

13. Marsot-Dupuch K, Matozza F, Firat MM, lyriboz AT, Chabolle F, et al. (1990) Mandibular nerve: MR versus CT about 10 proved unusual tumors Neuroradiology 2: 492-496

14. Oestmann A, Achtnichts L, Kappos L, Gass A, Naegelin Y (2008) ["Numb chin syndrome": first presenting syndrome of multiple sclerosis?] Dtsch Med Wochenschr 133: 76-78.

15. Sasaki M, Yamazaki H, Aoki T, Ota Y, Sekiya R, et al. (2011) Bilateral numb chin syndrome leading to a diagnosis of Burkitt's cell acute lymphocytic leukemia: a case report and literature review. Oral Surg Oral Med Oral Patho Oral Radiol Endod 111: e11-16.

16. Seve P, Gachon E, Petiot P, Stankovic K, Charhon A, et al. (2007) Successful treatment with rituximab in a patient with mental nerve neuropathy in primary Sjoren's syndrome. Rheumatol Int 28: 175-177.

17. Shahriar R, Alexander CT, Quirk CR, Keglovits L, Van Vrancken M (2012) Numb chin syndrome as the initial presentation of posttransplant lymphoproliferative disorder. J Proc (Bayl Univ Med Cent) 25: 243-245.

18. Cavallito C, Ferrera FD, Arduino PG, Broccoletti R, Carbone M (2013) Numb chin syndrome. Ann Stomatol (Roma) 4(Suppl 2): 10
19. Gooris PJ, Zijlmans JC, Bergsma JE, Mensink G (2014) A Case of menta nerve paresthesia due to dynamic compression of alveolar inferior nerve along an elongated styloid process. J Oral Maxillofac Surg 72: 1267.e1-7.

20. Sanabria Sanchinel AA, Flores Robles BJ, Santos Lasaosa S (2016) [Numb chin syndrome secondary to solitary schwannoma]. Med Clin (Barc) 147: 134.

21. Adachi M, Motohashi M, Kaku Y, Sugie S, Muramatsu Y, et al. (2018) Management consideration for patient with a large solitary fibrous tumor occupying the infratemporal fossa: a case report. Mol Clin Oncol 8: 544-548.

22. Arber DA, Orazi A, Hasserjian R, Thiele J, Borowitz MJ, et al. (2016) The 2016 revision to the World Health Organization classification of myeloid neoplasms and acute leukemia. Blood 127:2391-2405.

23. Dozzo M, Carobolante F, Donisi PM, Scattolin A, Maino E, et al. (2017) Burkitt lymphoma in adolescents and young adults: management challenges. Adolesc Health Med Ther 8: 11-29.

24. O'Conor GT. (1963) Significant aspects of childhood lymphoma in Africa Cancer Res 23:1514-1518.

25. Romo CG, Jain P, Cortes JE (2014) Numb chin syndrome by precursor B acute lymphoblastic leukemia. Am J Hematol 21: e920117-1-e920117-5.

26. Riesgo VJ, Delgado SR, Poveda J, Rammohan K (2015) Numb chin syndrome secondary to leptomeningeal carcinomatosis from gastric adenocarcinoma. J Gastrointest Oncol 6: E16-20.

27. Babikir MM, Mohamed SF, Nashwan AJ, Mudawi DS, Purayil SC, et al (2020) Acute Myeloid Leukemia Presenting with Numb Chin Syndrome: A Case Report and Review of Literature. Am J Case Rep 21: e920117.

\section{Acknowledgements}

We thank Michiel Brandt, MA, Monterey Institute of International Studies, albeit posthumously, for her 30 years of being "high on life" and her dedication and inspiration that made this study possible. Her death was due to an 8-year bout with leukemia. We are also greatly indebted to Takashi Katakura, $\mathrm{PhD}$, of the Department of Physiology, Kitasato University School of Medicine, for his technical assistance. 